\title{
ИНТЕРПРЕТАЦИЯ
}

\author{
М.А. Хасиева
}

\section{«РУССКИЙ ЮМОРИСТ»: ПРЕДСТАВИТЕЛИ ГРУППЫ БЛУМСБЕРИ О КАТЕГОРИИ КОМИЧЕСКОГО В ПРОИЗВЕДЕНИЯХ Ф.М. ДОСТОЕВСКОГО}

Аннотация. Предметом рассмотрения в данной статье являются интерпретации творчества Достоевского в критике В. Вулф и Л. Стречи. Интерес блумсберийцев к творчеству Достоевского, во многом предопределенный общеевропейским увлечением русской культурой и носивший ошутимый отпечаток колониального ориентализма, знаменовал при этом этап подлинного знакомства британской интеллигенции с русской литературой. При том, что в основных своих оценках поэтики Достоевского Вулф и Стречи были солидарны, они значительно расходились в характеристиках комедийной составляющей его произведений. Методология исследования включает в себя как обзор ряда произведений В. Вулф и Л. Стречи, так и герменевтический анализ данных текстов с учетом историко-культурного контекста восприятия творчества Достоевского в среде блумсберийцев. Научная новизна данной темы обусловлена малоисследованностью юмористического аспекта творчества Достоевского в европейской критике начала ХХ в. На основании обзора статей В. Вулф и Л. Стречи делаются выводы о сходствах и различиях их трактовок юмористической составляющей творчества Достоевского, а также выявляются истоки их критических позиций.

Ключевые слова: группа Блумсбери, В. Вулф, Л. Стречи, Ф.М. Достоевский, мениппея Достоевского, британский модернизм, Ч. Диккенс, Дж. Гиссинг, комическое у Достоевского, комедия реставрации.

Abstract. The subject of the present research is the interpretation of Dostoevsky's fiction by literary critics $V$. Woolf and L. Strachey. The Bloomsbury Group's interest in Dostoevsky's fiction was mainly predetermined by the overall Europe's fancy for the Russian culture and received a considerable impression of the colonial orientalism, however, signified the stage of the true acquaintance of British intellectuals with the Russian literature. Even though Woolf and Strachey had mostly the same evaluation of Dostoevsky's poetics, they had rather different opinions on the comic element of his fiction. The research methodology involves both a review of a number of works written by Woolf and Strachey and hermeneutic analysis of these texts considering historical and cultural environment that influenced the perception of Dostoevsky's fiction by the Bloomsbury Group. The scientific novelty of the research is caused by the fact that humour in Dostoevsky's fiction is an understudied topic in the European criticism of the early XXth century. By reviewing Woolf's and Strachey's articles the author of the present research draws conclusions about differences and similarities in Woolf's and Strachey's interpertation of humour in Dostoevsky's fiction and analyzes the grounds for their critical positions.

Key words: Ch. Dickens, British modernism in literature, menippea in Dostoevsky's works, F.M. Dostoevsky, L. Strachey, V. Woolf, Bloomsbury Group, G. Gissing, a sense of humor in Dostoevsky's works, Restoration comedy.

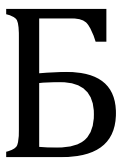

лумсберийцы вошли в круг почитателей творчества Достоевского задолго до опубликования собрания его сочинений в переводе Констанс Гарнетт, знакомясь с его романами по французским переводам. Их интерес, во многом предопределенный общеевропейским увлечением русской культурой и носивший ощутимый отпечаток колониального ориентализма, тем не менее, знаменовал наступление этапа под- линного знакомства британской интеллигенции с русской литературой.

Изначально романы Достоевского издавались “Vizetelli \& co." в переводах Ф. Уишоу в одной серии с бульварными французскими романами и воспринимались как детективы и авантюрные романы, произведения «легкого жанра». Лишь в начале XX в. B английской литературной критике появляются рассуждения о психологической многослойности и 
философской глубине его творчества, упрочилась его репутация пророка и мудреца. Юмористическая и комедийная составляющая творчества Достоевского долгое время оставалась европейцам неизвестной, отчасти из-за отсутствия перевода многих его ранних произведений, отчасти из-за этнокультурных стереотипов, бытовавших в британском обществе. С другой стороны, переосмысление ценностей викторианской культуры, произошедшее в Англии начала XX века, способствовало развитию открытого, непредвзятого интереса к инокультурной литературе и искусству, инициировало отказ от условностей морализаторской цензуры. В этот период были предприняты первые попытки апологии комедии Реставрации, долгое время подвергнутой остракизму за имморализм и «низовой» характер юмора. Представители группы Блумсбери приняли в этом процессе активное участие, высоко оценив исследование Джона Палмера «Комедия нравов», изданное в 1913 году.

Наибольший интерес к Достоевскому среди прочих представителей группы проявляли литераторы Литтон Стречи и Виржиния Вулф. Вулф принадлежит целый ряд работ, посвященных творчеству Достоевского, почти всегда рассматриваемого ею в контексте темы «русского влияния» на английскую литературу. В известной полемике с реалистами-эдвардианцами Вулф вполне однозначно относит Достоевского к числу своих сторонников и вдохновителей.

В 1917 году выходит эссе «Больше Достоевского», в котором Вулф, в тот период весьма увлеченная Достоевским, утверждает его превосходство над английскими писателями-реалистами. В 1919 году Вулф публикует статьи «Второстепенный Достоевский», и «Достоевский в Крэнфорде», где затрагивает, в том числе, и проблему юмора Достоевского. В программном эссе «Современная литература», относящемся к 1921 году, акцентируется обозначенная Вулф ранее идея о противостоянии «материалистов» и «спиритуалистов», формирующих модернистскую концепцию литературы во многом под влиянием русских писателей, в первую очередь Достоевского. Эссе «Русская точка зрения», изданное в 1925 году, преимущественно обобщает наработки и умозаключения, изложенные в «Современной литературе», «Второстепенном Достоевском», «Достоевском в Крэнфорде».

В 1922 году был опубликован перевод «Исповеди Ставрогина» на английский язык, выполненный Вулф совместно с С.С. Котелянским. Вклад Вулф в их работу заключался преимущественно в литературном редактировании текстов Котелянского, поскольку ее уровень владения русским языком оставлял желать лучшего, а его английский, в свою очередь, не был безупречным. История ее узнава- ния творчества Достоевского подробно отражена в ее переписке с Литтоном Стречи.

По свидетельству биографа Майкла Холройда, Стречи познакомился с творчеством Достоевского через своих друзей, художников Генри Лэмба и Огастаса Джона, ранних почитателей его произведений [7, с. 207]. Творчество Достоевского он активно обсуждал в своей переписке с Виржинией Вулф, неоднократно упоминал его в письмах к своему брату, психоаналитику, переводчику и издателю Джеймсу Стречи. Перу Литтона Стречи принадлежат два эссе, посвященные творчеству Достоевского. Первое эссе «Достоевский», впервые опубликованное в "Spectator" в 1912 г., представляет собой критическую рецензию на роман «Братья Карамазовы».

В данной рецензии, фокусируя свое внимание преимущественно на проблеме бессознательного в произведениях Достоевского, Стречи противопоставляет его английскому роману. Стречи подчеркивает при этом гуманистическую направленность его творчества: при том, что экстраординарность и контрастность его поэтики являются атрибутами нравственного экспериментирования, он является едва ли не самым «человечным» писателем.

К проблеме юмора Достоевского Стречи обращается позже, в публикации «Русский юморист», относящейся к 1917 г. Эссе является одним из первых исследований категории комического в произведениях Достоевского и потому представляет особый интерес. Начинается эссе с цитаты из письма 1888 года Георга Брандеса к Ницше, где приведен характерный и гротескно преувеличенный портрет «эпилептического гения» $[10$, с. 118$]$. Стречи отмечает, что большинство критиков, чрезмерно увлекаясь колоритом портрета Достоевского и его биографии, воспринимают его творчество слишком стереотипно и оставляют без внимания элемент юмора «замечательного и оригинального типа» [10, с. 118], присутствующий в его произведениях. Это объясняется, по его мнению, тем, что элемент юмора практически отсутствует в наиболее читаемых европейцами произведениях Достоевского, прежде всего в «Преступлении и наказании».

Среди «юмористических» произведений Достоевского Стречи выделяет повести «Дядюшкин Сон», «Вечный муж». Здесь Достоевский приближается к тому духу безудержной веселости, переходящий порой в откровенный фарс, который можно найти в «Лекаре поневоле» и «Жорже Дандене» Мольера. Сравнение с Мольером абсолютно точно угадывает замысел Достоевского, ведь из дневников писателя известно, что именно в мольеровских рогоносцах и ревнивцах он черпал материал для образа Трусоцкого. [10, 119]. Стречи фокусируется на абсурдизме произведений Достоевского, комбинации буффонады и здравого смысла, тон- 
ко подмечая основные пересечения его юмора с французской комедией нравов.

В «Бесах» и «Идиоте», как отмечает Стречи, юмор Достоевского обретает завершенные формы, выделяются наиболее характерные его черты: экстраординарность и неожиданность, психологическая проницательность в сочетании с гуманистической любовью ко «всему, что есть благородного в человеке» $[10$, с. 119]. Стречи проводит традиционное противопоставление эксцентричности и контрастности поэтики Достоевского сосредоточенному спокойствию, авторской центрированности повествования Толстого. По его мнению, именно в силу этих особенностей художественного мира Достоевского наличие юмора в его произведениях гораздо более значимо, чем у Толстого.

Контрастность, резкость и экстраординарность поэтики Достоевского оценивается Стречи весьма неоднозначно: «писательство такого рода может иметь много преимуществ; оно может возвести живой интерес, вовлеченность, энтузиазм читателя в самую высокую степень; но все это оборачивается одним риском - риском нереальности» [10, c. 119]. Стречи отмечает гротескную фантастичность художественного мира Достоевского, скандальность, эксцентричность и высокую степень эмоционального напряжения в массовых сценах [10, c. 118]. Он концентрируется именно на тех особенностях, которые впоследствии будут акцентированы M.M. Бахтиным в применении понятия менипповой сатиры к поэтике Достоевского (выдвижение на первый план «художественных категорий скандального и эксцентрического», «морально-психологическое экспериментирование», «трущобный натурализм») [2, c. 325]. О близости трактовки Стречи концепции Бахтина свидетельствуют и его размышления о Достоевском и Сервантесе. Прослеживая в сцене смерти Степана Трофимовича сюжетные мотивы финала «Дон Кихота», Стречи открывает иной, не замеченный большинством европейских критиков того периода тип комического у Достоевского.

Кроме сатирического начала и гротескного юмора Литтон Стречи выделяет у Достоевского более близкий сдержанной английской комедии «юмор сердечной доброты» ("Lovingkindness humour") [10, с. 119]. Он иллюстрирует эту разновидность комического примером сна Елизаветы Епанчиной в «Идиоте», вызвавшего столь бурное раздражение ее матери (часть III, глава I). Здесь речь идет о весьма характерном для Достоевского приеме, когда подчеркнутая прозаичность и обыденность происходящего в противопоставлении ожидаемому романтическому идеалу становятся предметом иронизирования над героем (еще один яркий пример этого - внешний облик черта, при- видевшегося Ивану Карамазову). Тот же тип юмора Стречи усматривает в образах шекспировского Фальстафа, дяди Тоби Лоренса Стерна.

Проблемы юмора у Достоевского касается и Вирджиния Вулф в своих работах. Развитию ее интереса к русской литературе во многом способствовало знакомство с С.С. Котелянским и совместная с ним работа по переводу произведений русских классиков (в частности, известно, что Вулф работала над переводом «Исповеди Ставрогина»). Биографы Вулф с полным основанием говорят о методологическом влиянии Достоевского на нее, поскольку «годы наиболее полного увлечения Вулф русской литературой, как критика и переводчика, совпадают с периодом, когда формируется ее экспериментальный нарративный метод» [8, с. 356].

В статье «Достоевский в Крэнфорде», впервые опубликованной 23 октября 1919 г., Вулф предлагает читателю провести мысленный эксперимент: «забавно иногда обновить наши представления о великой и потому полумифической фигуре, мысленно поместив ее в нашу собственную эпоху, в какой-нибудь маленький городок или деревенское поселение» $[11$, с. 120]. Развивая свою мысль о совершенной несовместимости образа Достоевского с размеренным укладом сельской жизни английского среднего класса, Вулф опрометчиво впадает в стереотип антитезы русского и английского, пытаясь затем перенести это противопоставление в свои суждения о поэтике романов Достоевского.

Переходя от личности писателя к его произведениям, Вулф проводит аналогию между Мордасовым, где происходит действие повести «Дядюшкин сон», и Крэнфордом, местом действия одноименного романа Элизабет Гаскелл. Подвергая анализу не отдельных героев, а художественное пространство, конструируемое писателями, она концентрируется на разительном контрасте скандальной, мелочной злобности общества уездного городка Мордасова и английской провинциальной идиллии романа Гаскелл: «Но Мордасов - место, весьма отличающееся от Крэнфорда: в напитках дамы не склонны довольствоваться чаем, а злобность их сплетен больше пристала базарной площади или рынку, чем светской гостиной. ... Они совершают свои мелкие грешки - подслушивание у замочной скважины или кража сахара в момент, когда прислуга выйдет из комнаты - с беззастенчивой наглостью сварливых мегер» [11, с. 121].

Развивая свою мысль о противоположности Крэнфорда и Мордасова как репрезентаций художественных миров Гаскелл и Достоевского, Вулф заключает, что недостаток английской классической прозы с лихвой возмещается психологической достоверностью и философской глубиной его произведений. Рассматривая проблему юмора Достоевского 
на материале рассказов «Дядюшкин сон», «Крокодил», «Скверный анекдот», Вулф весьма односторонне определяет юмор Достоевского, как сатиру или фарс. Рассматривая повесть «Дядюшкин сон» как произведение «легкой формы», она концентрируется на резкости и тяжеловесности его юмора: «Достоевский не может долго придерживаться этой легкой манеры. Его язык становится резким, а настроение насильственным, он <..> отличается рассеяностью великого ума, слишком уставшего, чтобы сконцентрироваться, и слишком перегруженного, чтобы приостановиться» $[11$, с. 122]. Это же касается и «Скверного анекдота», где склонность Достоевского обращаться к предыстории описываемых событий, его углубления в житейские обстоятельства героев представляются ей избыточной [11, с. 123].

Отмечая разительное несходство комического начала творчества Достоевского с образцами английского юмора XIX столетия, сдержанного и консервативного, Вулф сближает его поэтику с юмористическим стилем Уичерли: «Его комедия имеет гораздо больше общего с комедией Уичерли, чем с комедией Джейн Остин, она быстро переходит к первоосновам и становится беспорядочным, экстравагантным фарсом. Отвлеченность и беспристрастность великих комических писателей для него невозможна» [11, с. 122]. Здесь Вулф близка видению Стречи, учитывая общеизвестное влияние французской комедии нравов, и в первую очередь Мольера, на английскую комедию эпохи реставрации. Фабулу и ролевые характеристики героев Достоевского и Уичерли роднят между собой карнавальное начало, мотив травестии и маски.

Однако Вулф осознает и ключевое различие между его поэтикой и произведениями Уичерли. В пьесах Уичерли циническое низведение изображаемых нравов до уровня скандального, «площадного» обусловлено, прежде всего, реалиями культурно-исторического этоса и передает дух либертинского гедонизма, свойственный аристократической прослойке той эпохи. У Достоевского же эта сатира обретает статус искусственно создаваемого фасада, скрывающего многослойность конструируемого им семиотического пространства. Именно поэтому вслед за Морисом Бэрингом Вулф определяет Достоевского прежде всего как «мудреца» и «пророка», а не как юмориста [15, с. 278].

В критическом обзоре «Фазы литературы», представляющем собой «попытку запечатлеть впечатления и умозаключения от ряда романов в определенной последовательности» [14, с. 123], Вулф пытается определить и классифицировать особенности различных повествовательных методов в единой эволюции литературных форм и жанров. Отнеся Достоевского вместе с Прустом и Генри Джеймсом к одной разновидности писателей - «психологам» [15, с. 275], Вулф акцентирует тем самым его принадлежность к когорте модернистов. Психологи, в отличие от прочих разновидностей писателей («правдивых рассказчиков», «романтиков», «живописателей характеров и комедиографов», «сатириков и фантастов», «поэтов»), не предоставляют «опору для читателя», выражающуюся во внешнем авторском нарративе, выстраивая сюжетно-событийную ориентацию произведения из фрагментов внутреннего монолога героев и их эмоциональных состояний $[15,277]$. Именно поэтому в произведениях «психологов» ключевой поворот, «кризис» сюжета всегда происходит в сознании персонажа. Но и сам метод письма «психологов» отнюдь не гетерогенен. Для иллюстрации различий в нарративных техниках писателей Вулф рассматривает «Что знала Мейзи» Джеймса, «В поисках утраченного времени» Пруста, «Бесы» Достоевского. Достоевского в сравнении с Прустом она называет «определенным» [Woolf, 15, с. 278], отмечая удивительную цельность, силу и полярность испытываемых его героями эмоций, в отличие от размытой и холодноватой отстраненности героев Пруста.

Окончательно определив Достоевского как «психолога» и мистика, Вулф не находит нужным вернуться к нему, когда рассматривает группу «сатириков и фантастов». Включив в эту группу Пикока, Троллопа, Стерна, она намеренно игнорирует Вольтера и Анатоля Франса «в пользу того, кто пишет на английском языке». Здесь же она пишет о «растущей невыносимой усталости от прочтения Достоевского, словно при чтении в неправильно подобранных очках или в тумане, образовавшемся над страницами книги» [16, с. 404]. Причина подобного «отстранения» Достоевского от сообщества сатириков состоит вовсе не в том, что производимая Вулф классификация предполагает выделение у писателя лишь одной характерной дефиниции: Троллопа она определяет одновременно и как «сатирика», и как «правдивого рассказчика». Это связано, скорее, с тем смыслом, который она вкладывает в определение двух этих категорий писателей, во многом их противопоставляя: «сатирик не трудится, подобно психологу, под гнетом всеведения. Он имеет возможность играть в своем сознании свободно и иронично. Его симпатии не определены столь глубоко, а чувство юмора не скрыто» [16, с. 405]. Точно так же Вулф отделяет Достоевского и от Диккенса, отнеся последнего к классу «живописателей характеров». Сопоставляя живописателей характеров с «психологами», Вулф отмечает, что основной фокус действия в произведениях первых сконцентрирован на внешних событиях, в то время как в произведениях психологов, в первую очередь Достоевского, акцент смещен на внутренний психологический 
конфликт героев. Словно предвосхищая слова Барта о смерти автора, Вулф заявляет о «кризисе» литературы, когда «привычные ориентиры, вехи и опоры умозаключений писателя, выраженные или описанные им, устранены» [15, с. 275]. Справиться с этим кризисом традиционными средствами оказывается невозможным: «убийства, изнасилования, соблазнения, внезапные смерти не имеют никакой власти над этим высоким, отстраненным миром» [15, c. 275]. Достоевский видится ей создателем нового типа нарратива, именно этим он противопоставлен Диккенсу, Джейн Остин и Джордж Эллиот.

Противопоставление Достоевского и Диккенса, намеченное Вулф, весьма знаково, поскольку расходится с суждениями других критиков, сравнивавших их юмор. Еще в 1898 году было опубликовано исследование Д. Гиссинга «Чарльз Диккенс», привлекшее большое внимание современников и, несомненно, знакомое Вулф. Гиссинг отмечает в своем исследовании сходство поэтики Диккенса и Достоевского, выражающееся в гуманистическом пафосе и, в особенности, в тональности юмора их произведений [6]. И, хотя Гиссинг не считает нужным останавливаться на этом сходстве, юмор Диккенса он рассматривает весьма подробно. В главе восьмой он разделяет комические приемы Диккенса на фарс и подлинный юмор. Фарс несет в себе главным образом развлекательную функцию, порой своей экстравагантностью призван смягчить неприглядную и жестокую правду жизни. Юмор же Диккенса всегда обращен к человеческой природе, призван раскрыть характер персонажа или, по крайней мере, проиллюстрировать нравы общества. По всей видимости, именно этот тип комического Гиссинг усматривает также и у Достоевского. Весьма близкий этому смысл вкладывает Стречи в свое понятие «юмора сердечной доброты», присутствующего у Достоевского. Вулф же, в отличие от Стречи и Гиссинга, отказывается воспринимать произведения Достоевского в этом ракурсе, а потому и не пытается связать его с Диккенсом, Стерном, Сервантесом.

В целом Гиссинг склонен видеть в Достоевском не только реалиста, подобного Диккенсу, но и морализатора. Правомерность подобной трактовки отчасти подтверждается и отечественными исследователями, в частности, определением M.М. Бахтина мениппеи Достоевского как «церковно-проповеднической» [1, с. 746]. Гиссинг, впрочем, также признает большие различия художественных миров писателей. Так, импонирующий ему натурализм Достоевского контрастирует с викторианской чопорностью Диккенса: «его превосходство как реалиста над автором «Дэвида Коперфилда» состоит, главным образом, в откровенном изображении фактов, которые Диккенс обречен умалчи- вать или упоминать вскользь, со вздохом робости» [6]. Да и причины, толкающие героев Диккенса на самоубийство или убийство, слишком вульгарны и прозаичны, по сравнению со сложной философской мотивацией героев Достоевского. Тем не менее, симпатизирующий Достоевскому Гиссинг причисляет его к реалистам, что близко его собственному художественному методу. Вулф же, напротив, видит в его творчестве выход за пределы привычной авторской дидактики и морализаторства.

Эссе «Больше Достоевского», опубликованное впервые в «Литературном приложении Таймс» 22 февраля 1917 года, посвящено изданному в переводе Констанс Гарнетт сборнику повестей: «Кроткая», «Вечный муж», «Двойник». Рассматривая фабулу повести «Вечный муж», Вулф отмечает значимость предыстории в отношениях Вельчанинова и Трусоцкого, способствующую раскрытию сложной психологической ситуации, поставленной в центр произведения.

В эссе «Второстепенный Достоевский» (11 октября 1917 года) она утверждает, что интуиция подводит Достоевского в повестях «Игрок», «Бедные люди», «Хозяйка», которые, по сравнению со столь «мощными романами», как «Идиот»и «Братья Карамазовы», представляются ей скорее «набросками», лишенными психологической глубины и многослойности [12]. Рассматривая сцену у рулетки в «Игроке», когда генерал и де Грие пытаются увести проигрывающую состояние старуху, Вулф пишет об «удивительном юмористическом эффекте, который она производит» [12]. Причем самобытность этой сцены она видит именно в ее краткости: всего двумя фразами, как бы мимоходом Достоевский умудряется создать комичность происходящего, в то время как английский писатель развернул бы целую интерлюдию.

Р. Рубинштейн упоминает, что в период работы над романом «Миссис Дэллоуэй» (1922-1925 годы) Вулф также сделала наброски к эссе о русской комедии с рабочим названием «Русское чувство комедии, Достоевский и комедия в целом». Однако замысел этот остался невоплощенным, а в «Русской точке зрения», опубликованной в том же году, что и «Миссис Дэллоуэй», Вулф уже заявляет, что дух произведений Достоевского лишь «в малой степени наделен чувством юмора и почти начисто лишен чувства комедии» [9, с. 39]. Этим обстоятельством Вулф и объясняет трудность, с которой английский читатель (и, по всей видимости, она сама) воспринимает произведения Достоевского.

Наиболее характерные дефиниции поэтики Достоевского Вулф рефреном воспроизводит в своих статьях и переписке. Это, в первую очередь, противопоставление глубокой и достоверной репре- 
зентации человеческого сознания у Достоевского художественному методу реалистов-эдвардианцев: «Этот метод прямо противоположен тому, что используется большинством наших новеллистов. Они воспроизводят внешние атрибуты, <..> но очень редко и лишь мельком затрагивают море мыслей, бушующее в его сознании» [11, с. 121]. Касаясь же комедийной составляющей произведений Достоевского, она неоднократно подчеркивает резкость, некоторую тяжеловесность его юмора и «насильственный» эффект, который он производит на читателя [11, с. 123$]$.

Сопоставление оценок поэтики Достоевского у Стречи и Вулф обнаруживает как некоторое сходство, так и существенные расхождения. Основная ценность наблюдений Стречи в эссе «Русский юморист» состоит, прежде всего, в раскрытии многообразия юмора Достоевского. Стречи ищет в его творчестве параллели с европейской комедией, что, несомненно, гораздо более перспективно, нежели стереотипное противопоставление творчества Достоевского как квинтэссенции иррациональных и противоречивых переживаний реалистической эдвардианской литературе, на котором порой слишком сосредотачивалась Вулф. В отличие от Вулф, склонной видеть в комедии Достоевского «насильственную усмешку, порой начисто лишенную веселья» [11, с. 123], Стречи воспринимает его юмор более разносторонне и непредвзято. Подобный интерпретативный ракурс позволяет увидеть в произведениях Достоевского элементы классической комедии положений («Чужая жена и муж под кроватью»), абсурдистской комедии («Крокодил»). Стречи не всегда понимает и одобряет методы Достоевского (не случайно он пишет об эффекте «нереальности», который возникает из-за гипертрофированной гротескности и наличия элементов фантастики и абсурда в его художественном мире), но при этом он более внимателен и беспристрастен, менее подвержен стереотипной русофильской восторженности. Вулф же, хотя и выходит за пределы поверхностной «салонной» увлеченности Достоевским, в то же время порой слишком однозначна и стереотипна в своей оценке масштабов и разносторонности комического начала в его произведениях. Она склонна противопоставлять юмор Достоевского традиционному «английскому юмору», безоговорочно признавая его авторитет как психолога и философа, но в качестве юмориста представляя его мрачным и утомительным. Природа подобного амбивалентного отношения к Достоевскому определялась во многом стереотипами общеевропейской увлеченности русской культурой. Коннотации подобной трактовки отчасти можно найти в высказывании Д.П. Святополка-Мирского в рецензии на книгу Стивена Грэма «Неизвестная Россия»: «Соприкосновение с русской культурой гибельно для всех лучших качеств англичанина и, особенно, для его прославленного “чувства юмора". <..> Проникнутый "русским духом" англичанин делается мрачным истериком и архаическим педантом» [4, с. 104].

Разнородность толкований юмора Достоевского у Стречи и Вулф определяется расхождением их интерпретаций его творчества в целом. Стречи видит в Достоевском светского гуманиста, Вулф - «пророка» и мистика. Эксцентричность, контрастность поэтики Достоевского Стречи склонен относить, так же, как и Бахтин, к области поэтики, воспринимать как атрибут жанрово-стилистической принадлежности. Вулф же зачастую переносит характеристики нарративной техники на авторское мировоззрение и идейное содержание произведений.

Истоки подобного одностороннего толкования юмора в произведениях Достоевского происходят отчасти из ее склонности противопоставлять сатирическую и сентиментальную разновидности комедии. Это противопоставление исторически восходит к бытовавшему в английской литературе XVIII века противостоянию сентиментализма и сатирического бытописания, отразившемуся в литературной полемике Филдинга и Ричардсона, в антитезе комедии реставрации и сентиментальной комедии в лице Р. Камберленда и Р. Стила. Позднее в английской литературе происходит согласование двух этих начал, в произведениях Диккенса, например, как отмечает Гиссинг, прослеживается уже эклектичное совмещение фарса и сентиментального юмора. Стречи, как и Гиссинг до него, видит юмористический диапазон Достоевского столь же широким и многообразным, как у Диккенса. Интерпретация Вулф же остается детерминированной координатами двух противопоставленных полюсов, сентиментального юмора и сатиры, к которой она и причисляет произведения Достоевского, отмечая при этом, что философскопсихологическое содержание в них всегда превалирует над юмористическим.

В целом же отношение блумсберийцев к творчеству Достоевского не было абсолютно гетерогенным и определялось не столько их общим эстетическим манифестом, сколько индивидуальным исследовательским наитием, личными литературными предпочтениями и способностью к непредвзятой критике. Рассмотренные статьи, не претендующие на фундаментальность и значительно отличающиеся в своей трактовке от русской критики, содержат, тем не менее, весьма ценные наблюдения, заложившие фундамент для последующих исследований, возобновившихся в Британии после периода некоторого охлаждения интереса к Достоевскому в 30-е годы XX в. 


\section{Список литературы:}

1. Бахтин, М.М. Мениппова сатира // Бахтин М. М. Собрание сочинений. Т. 4 (1). М., 2008. С. 54.

2. Бахтин, М.М. Проблемы поэтики Достоевского // Проблемы поэтики Достоевского. Проблемы творчества Достоевского. Киев, 1994, 511 с.

3. Биллингтон, Джон. Икона и топор. Опыт истолкования истории русской культуры. М.: Рудомино, 2001, 879 с.

4. Казнина О.А. Русские в Англии: русская эмиграция в контексте английских литературных связей в первой половине XX в. М.: Наследие, 1997, 413 с.

5. Baring, Maurice. Landmarks in Russian Literature.-London: Methuen and Co., 36 Essex Street W.G., 1910.299 p.

6. Gissing, George. Charles Dickens: A critical study // The University of Adelaide library. 1998-2015. ebooks.adelaide.edu.au: eBooks@Adelaide.URL: https://ebooks.adelaide.edu.au/g/gissing/george/charles-dickens/

7. Kaye, Peter. Dostoevsky and English modernism (1900-1930). Cambridge University Press, 1999,248 p.

8. Marcus, Laura. The European dimensions of the Hogarth press // The reception of Virginia Woolf in Europe/ Ed. by M.A. Caws and N. Luckhurst. NY, 2002, 449 p.

9. Rubinstein, Roberta. Virginia Woolf and the Russian Point of view. NY: Palgrave Macmillan, 2009, 288p.

10. Strachey, Lytton. Russian humorist // Strachey, Lytton. Literary essays. N.Y.: Harcourt, 1969, p.p. 17-20.

11. Woolf, Virginia. Dostoevsky in Cranford // Books and Portraits, ed. by Mary Lyon. New York: Harcourt Brace Jovanovich, 1978, p.p.120-123.

12. Woolf, Virginia. Minor Dostoevsky // Times Literary Supplement, London: News UK, October 1917,

13. Woolf, Virginia. More Dostoevsky // Books and Portraits, ed. by Mary Lyon. New York: Harcourt Brace Jovanovich, 1978, p.p. 116-120.

14. Woolf, Virginia. Phases of fiction: Part I // The Bookman, London: Hodder \& Stoughton, April 1929, p.p. $123-132$.

15. Woolf, Virginia. Phases of fiction: Part II // The Bookman, London: Hodder \& Stoughton, May 1929, p.p. $269-279$.

16. Woolf, Virginia. Phases of fiction: Part III // The Bookman, London: Hodder \& Stoughton, June 1929, p.p. 404-412.

17. Woolf, Virginia. The Russian point of view // The University of Adelaide library. 1998-2015. ebooks.adelaide.edu.au: eBooks@Adelaide.URL: https://ebooks.adelaide.edu.au/w/woolf/virginia/w91c/chapter16.html

\section{References (transliterated):}

1. Bakhtin, M.M. Menippova satira // Bakhtin M. M. Sobranie sochinenii. T. 4 (1). M., 2008. S. 54.

2. Bakhtin, M.M. Problemy poetiki Dostoevskogo // Problemy poetiki Dostoevskogo. Problemy tvorchestva Dostoevskogo. Kiev, 1994, $511 \mathrm{~s}$.

3. Billington, Dzhon. Ikona i topor. Opyt istolkovaniya istorii russkoi kul'tury. M.: Rudomino, 2001, 879 c.

4. Kaznina O.A. Russkie v Anglii: russkaya emigratsiya v kontekste angliiskikh literaturnykh svyazei v pervoi polovine XX v. M.: Nasledie, 1997, $413 \mathrm{~s}$.

5. Baring, Maurice. Landmarks in Russian Literature.-London: Methuen and Co., 36 Essex Street W.G., 1910. 299 p.

6. Gissing, George. Charles Dickens: A critical study // The University of Adelaide library. 1998-2015. ebooks.adelaide.edu.au: eBooks@Adelaide.URL: https://ebooks.adelaide.edu.au/g/gissing/george/charles-dickens/

7. Kaye, Peter. Dostoevsky and English modernism (1900-1930). Cambridge University Press, 1999, 248 p.

8. Marcus, Laura. The European dimensions of the Hogarth press // The reception of Virginia Woolf in Europe/ Ed. by M.A. Caws and N. Luckhurst. NY, 2002, 449 p.

9. Rubinstein, Roberta. Virginia Woolf and the Russian Point of view. NY: Palgrave Macmillan, 2009, 288p.

10. Strachey, Lytton. Russian humorist // Strachey, Lytton. Literary essays. N.Y.: Harcourt, 1969, p.p. 17-20.

11. Woolf, Virginia. Dostoevsky in Cranford // Books and Portraits, ed. by Mary Lyon. New York: Harcourt Brace Jovanovich, 1978, p.p.120-123.

12. Woolf, Virginia. Minor Dostoevsky // Times Literary Supplement, London: News UK, October 1917,

13. Woolf, Virginia. More Dostoevsky // Books and Portraits, ed. by Mary Lyon. New York: Harcourt Brace Jovanovich, 1978, p.p. 116-120.

14. Woolf, Virginia. Phases of fiction: Part I // The Bookman, London: Hodder \& Stoughton, April 1929, p.p. 123-132.

15. Woolf, Virginia. Phases of fiction: Part II // The Bookman, London: Hodder \& Stoughton, May 1929, p.p. $269-279$.

16. Woolf, Virginia. Phases of fiction: Part III // The Bookman, London: Hodder \& Stoughton, June 1929, p.p. 404-412.

17. Woolf, Virginia. The Russian point of view // The University of Adelaide library. 1998-2015. ebooks.adelaide.edu.au: eBooks@Adelaide.URL: https://ebooks.adelaide.edu.au/w/woolf/virginia/w91c/chapter16.html 